\title{
Large Scale Laboratory and Field Tests of Aerogel Renders
}

\author{
Jürgen Frick ${ }^{1}$, Nayara R. M. Sakiyama ${ }^{1,2}$, Marina Stipetic ${ }^{1}$ and Harald Garrecht $^{1}$ \\ ${ }^{1}$ Materials Testing Institute (MPA), University of Stuttgart, Pfaffenwaldring 2b, 70569 Stuttgart, \\ Germany, juergen.frick@mpa.uni-stuttgart.de \\ ${ }^{2}$ Institute for Science, Engineering and Technology (ICET), Federal University of the Jeq. and Muc. \\ Valleys (UFVJM), R. Cruzeiro, 01 -Jardim São Paulo, 39803-371 Teófilo Otoni, Brazil, \\ nayara.sakiyama@ufvjm.edu.br
}

\begin{abstract}
Within the framework of the European project Wall-ACE a large-scale laboratory test (EOTA-Wall Test) was performed. Additional a test field in Switzerland was equipped with six different aerogel renders by the project partner AGITEC. Laboratory walls and test field were equipped with sensors to monitor in real-time climate, heat flux, temperature, relative humidity, and at the laboratory tests additional material moisture. The data allow calculating U-values and material parameters as well as drying behaviour of render and substrate. During and after the artificial weathering in laboratory the renders were subjected to visual inspection and mechanical adhesion tests. The performance of the aerogel renders will be assessed and compared with results on conventional insulation renders.
\end{abstract}

Keywords: Aerogel, External Insulation.

\section{Introduction}

As the European Union (EU) requires an improvement of 27\% regarding the buildings energy efficiency by 2030 (European Commission), the development of innovative technologies to improve the performance levels of the building envelop is encouraged. In this sense, the Horizon 2020 project (Wall-ACE, 2016) aimed to develop a package of new advanced aerogelbased insulation products and systems that could be used to strengthen the competitiveness of Europe through innovation and excellence. Among the developed products was an external high performance insulating render, which had as goals providing a long lasting, breathable continuous insulation layer where its thickness could be adjusted depending on the climate, on the geographic orientation of the wall and on architectural or specific local needs (thermal bridges, uneven walls, windows reveals, architectural constraints such as in semidetached housing, etc.).

Within the framework of the project there were included tests to assess the efficiency and behaviour of the different insulation systems in extreme conditions in large-scale tests and real conditions on building scale.

\section{Experimental}

\subsection{EOTA-Wall Test}

To assess the durability of the external insulation render developed by the Wall-ACE project partner Quick-Mix, a large-scale laboratory test (EOTA-Wall test) was performed according to (EN 16383:2016). 


\subsubsection{Test set-up}

The test chamber consists of two opposing walls spaced one meter apart, with the render system facing each other, forming an inner room that characterizes the outside conditions. On one of the chamber sidewalls, the Quick-mix external render, an aerogel-based exterior insulation render was applied, while on the other side a commercially available, regular perlite-based insulation render, TRI-O-THERM, was used as a reference material. Each wall was split vertically and was made up of bricks on one side and concrete blocks on the other, measuring in total $4.0 \times 2.1 \mathrm{~m}$ (length $\mathrm{x}$ high). Therefore, it can be considered that four walls were under investigation, named here from A to D, see Figure 1.
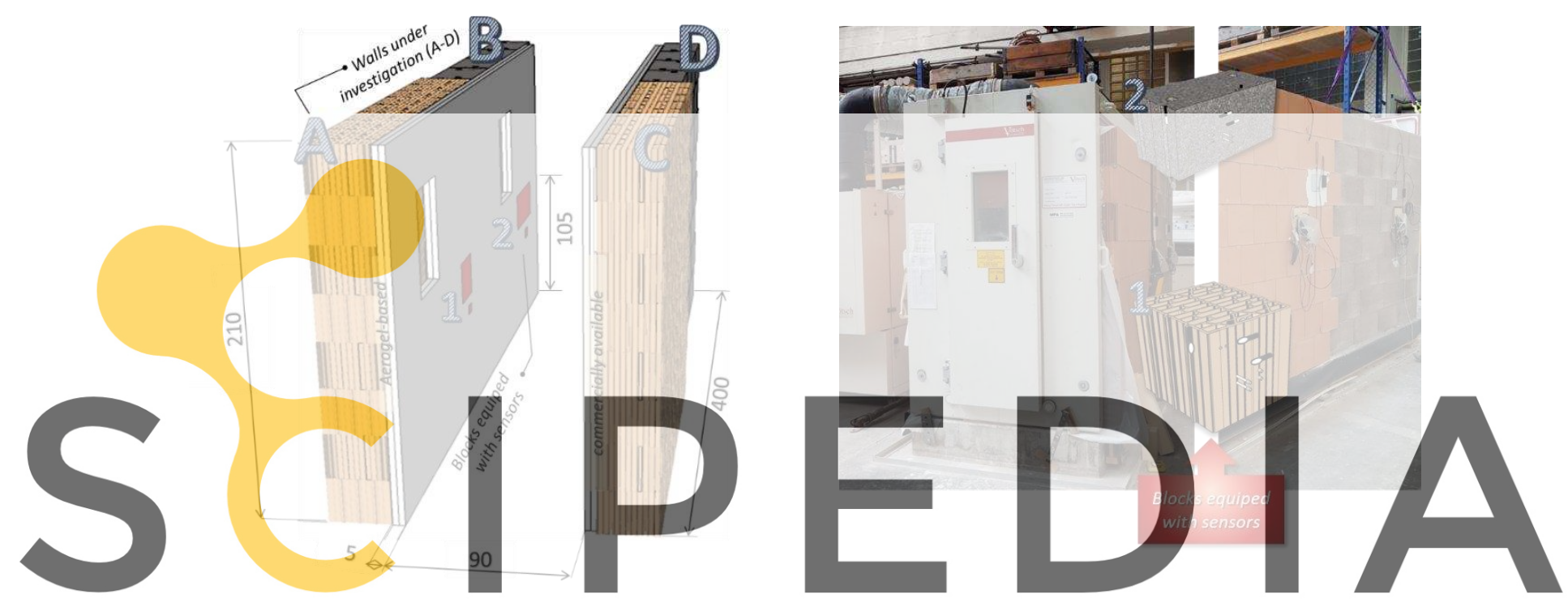

Figure 1. Left: Aerogel render wall (A, B), perlite render wall (C, D). Right: EOTA test rig and monitoring Register for free at https//www.scipedia.com fosteflownload the version without the watermark

The set-up of both walls are as following: 1 Substrate: bricks or concrete blocks, 2 adhesion layer (concrete blocks), 3 exterior insulation render: two layers of around $3 \mathrm{~cm}$ of aerogel or perlite render, 4 two layers of supporting plaster together with a reinforced mesh in the first layer, 5 hydrophobic final coting. Such solution is necessary to ensure both mechanically stability and protection from weathering and mechanical impact.

\subsubsection{Durability test - weathering cycles}

The large-scale test walls were exposed to weathering cycles according to (EN 16383:2016), which are grouped into heat-rain, heat-cold and heat-rain-cold cycles, see Figure 2. Lasting on average 84 days, the ageing test offers harsh conditions with a $90^{\circ} \mathrm{C}$ temperature range and $1.51 / \mathrm{m}^{2} \mathrm{~min}$ amount of water during the rain cycles.

\subsubsection{Material moisture and temperature monitoring}

On each of the four monitored walls, one concrete or brick block equipped with impedance and hygro-thermal sensors was placed among the layered blocks (Figure 1). Impedance sensors, which consist of two probes (screws or thread rod) surrounded with a conduction rubber at a 
proximity distance of $1.5 \mathrm{~cm}$ were incorporated in the bricks, joints and exterior render layers. Additional, hygro-thermal sensors were installed as well and covered with a porous tube or with a glass fibre tape. The used hygro-thermal sensors (Sensirion SHT25) have a small size $(3 \times 3 \times 1.1 \mathrm{~mm})$ and a resolution of $\pm 0.2 \mathrm{~K}$ and $\pm 1.8 \% \mathrm{RH}$.
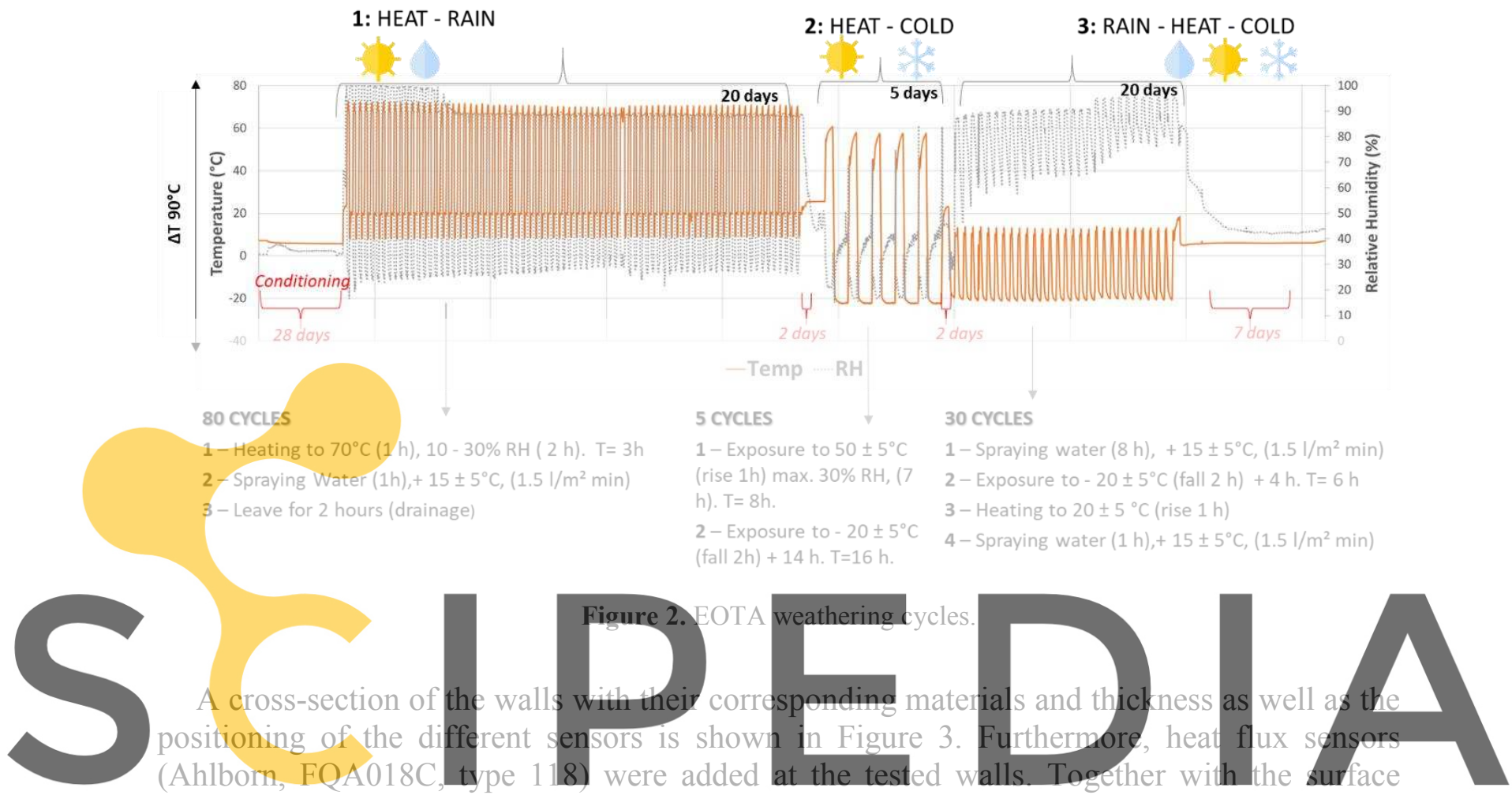

temperature measurements, the wall thermal resistance or U-value, according to (ISO 9869-

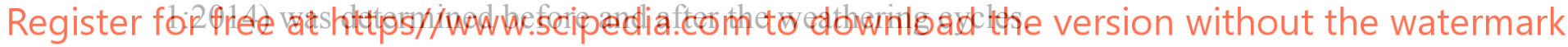
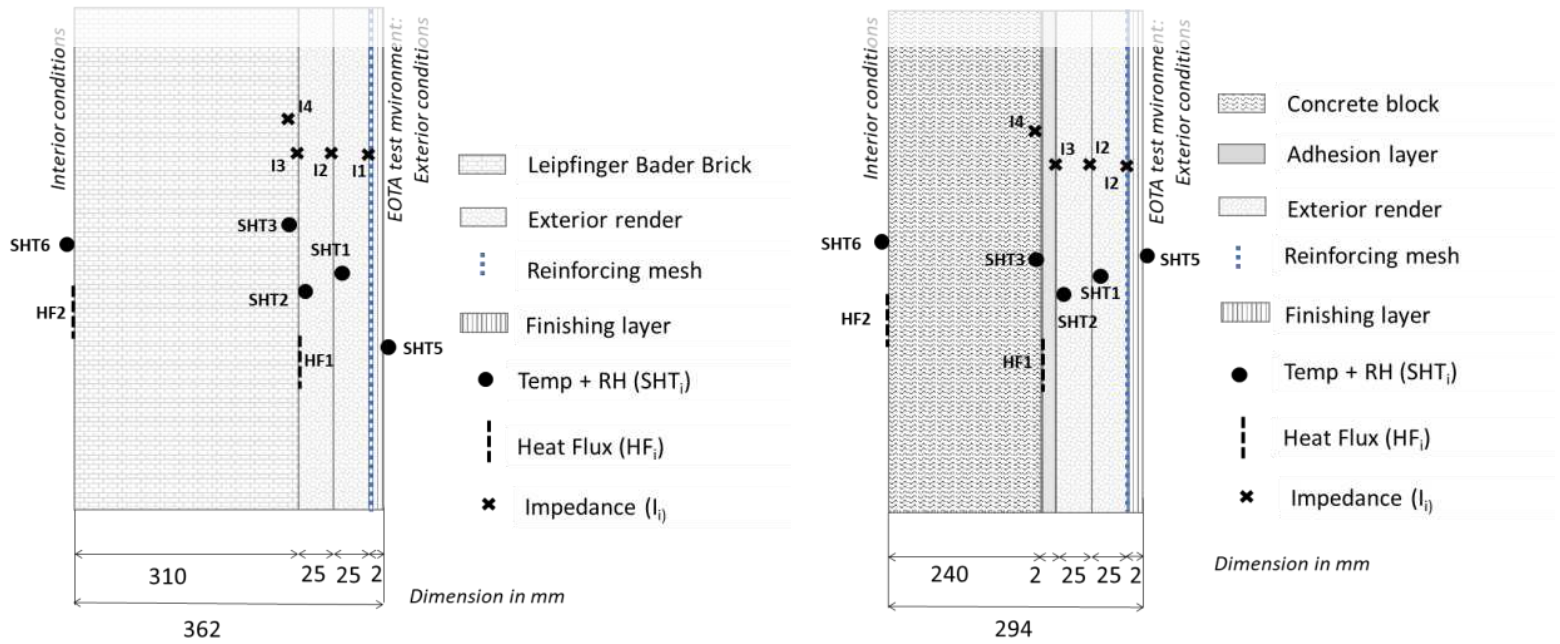

a) Brick walls (A and C)

b) Concrete block walls (B and D)

Figure 3. EOTA test - walls sections (A-D). 


\subsubsection{Adhesive strength}

Adhesive strength between insulation render and substrate was tested according to (ETAG 004:2013, Section 5.1.4.1.1, Paragraph 2). Adhesive strength was tested after the weathering cycles for both renders: developed aerogel-based and commercially available TRI-O-THERM.

Results of adhesive strength before weathering cycles represent initial adhesive strength. For testing of adhesive strength, square test surfaces with $50 \mathrm{~mm}$ edge length was chosen. The edges of the test surfaces $(50 \mathrm{~mm}$ edge length) were dry-cut through the insulation render until substrate surface. A metal plate with an edge length of $50 \mathrm{~mm}$ was glued to each test surface using a 2-component adhesive based on epoxy resin. After sufficient hardening of the adhesive, the metal plate was pulled off using a pull-out testing device, see Figure 4.

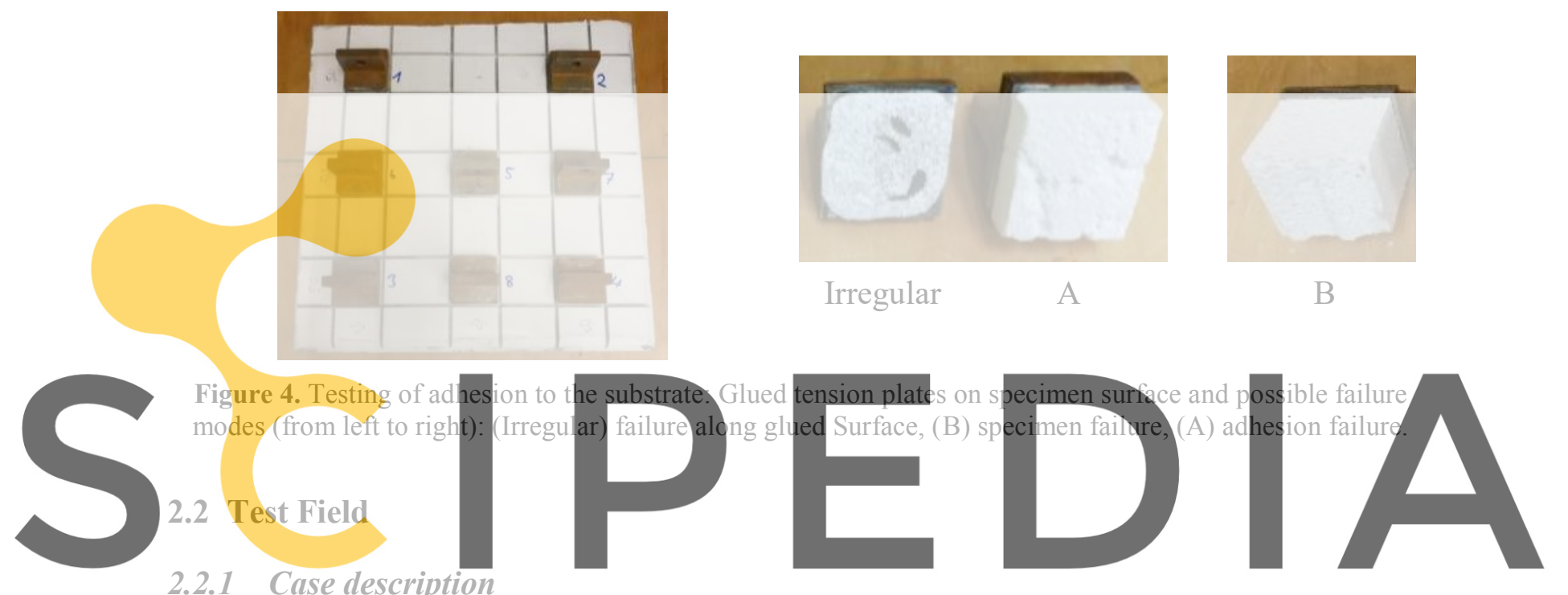

\subsubsection{Case description}

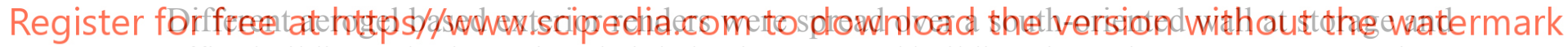
office building to both monitor their behaviour at a real building site and to pursue a comparison study to evaluate its performance. The wall under investigation stand to the left of the main entrance of AGITEC industrial shed building, located in Dällikon - Switzerland, close to the Zurich $\left(47^{\circ} 26^{\prime} 44.3^{\prime \prime} \mathrm{N} 8^{\circ} 26^{\prime} 26.2^{\prime \prime} \mathrm{E}\right)$.

In details, the industrial shed area is the ground floor of the building with a total height of $7.07 \mathrm{~m}$, and gross external dimensions of $15.20 \mathrm{~m}$ x $39.32 \mathrm{~m}$. It has a prefabricated concrete structure, composed of pillars spaced every $6.5 \mathrm{~m}$. Moreover, the warehouse has MDF and plasterboard partitions, both vertical (internal walls) and horizontal (floor slabs), thus creating small deposits in its interior space. These deposits have an average height of $3.10 \mathrm{~m}$.

Regarding the analysed materials, four commercially available aerogel renders (anonymized data: A to D), and Quick-Mix Wall-ACE renders 1\&2 (Figure 6) are studied. Firstly, the four commercially available aerogel renders (A-D) were applied to the industrial shed south façade with an area of $5.5 \mathrm{~m}^{2}$ each. Later on, Quick-Mix Wall-ACE renders 1\&2 were applied alongside the others, having an area of respectively $23 \mathrm{~m}^{2}$ and $10 \mathrm{~m}^{2}$. The application followed the following scheme: 1 cleaning, primer and roughcast for adhesion, 2 two layers of aerogel insulation render by machine spraying, 3 two layers of supporting plaster (the same for all walls) together with a reinforced mesh in the first layer, 4 final coting. 


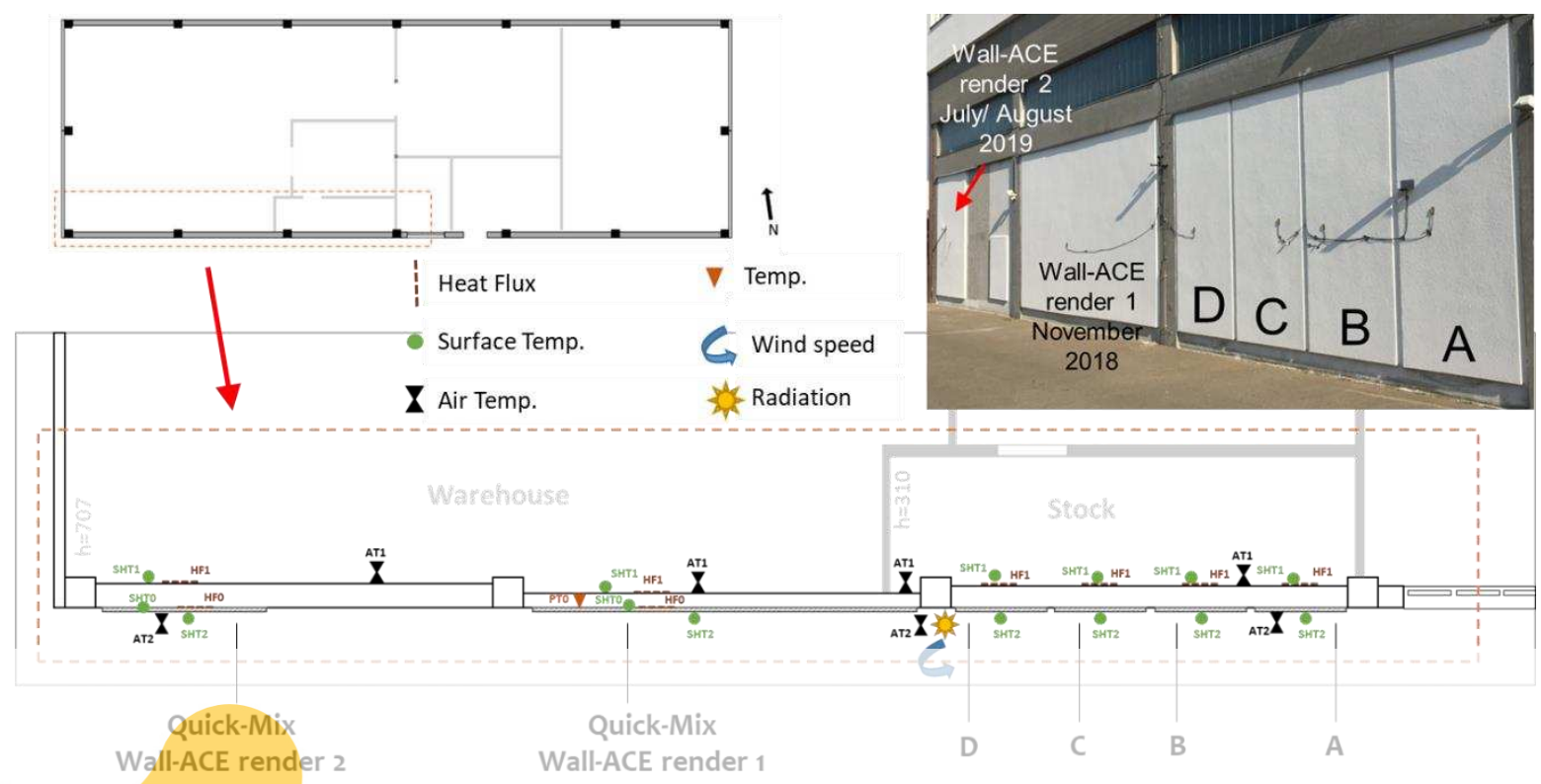

Figure 5. Floor plan: AGITEC storehouse. Feature test walls, sensors and installation.

\subsubsection{Monitoring}

Both environment/boundary conditions and walls elements were equipped with sensors to allow, through on-site measurements, an in situ thermal characterization and consequently. performance analysis of the different adrogel render products under investigation. For this, air tempera warehouse and stock (Sensirion SHT31). Hea inner side for all tested materials, and additionally between the Quick-Mix Wall-Ace exterior

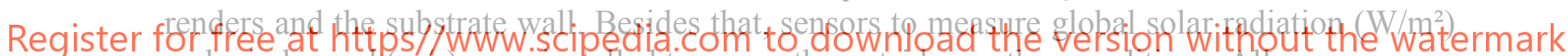
and wind speed $(\mathrm{m} / \mathrm{s})$ were installed to assess the outside weather conditions. All sensors were placed approximately at $1.5 \mathrm{~m}$ high (see Figure 6). However, the presence of outdoor weather conditions configures a challenge to estimate a stationary parameter such as thermal resistance. Moreover, the average method, described in ISO 9869-1:2014, requires walls not exposed to direct solar radiation, which is not the case here.

Furthermore, it is emphasized that the composition of the storehouse walls differ from each other, presenting distinct thicknesses and materials, according to their location (Figure 1), which also has different heights (warehouse $=7.07 \mathrm{~m}$ and stock $=3.10 \mathrm{~m}$ ). All these factors make an instant comparison between the renders difficult.

\section{Results and Discussion}

\subsection{EOTA-Wall Test}

\subsubsection{Material moisture and temperature monitoring}

The temperature difference across the brick and concrete block walls $\left(\Delta \mathrm{T}={ }^{\circ} \mathrm{C}\right)$, as well as both heat flux $\left(\mathrm{W} / \mathrm{m}^{2}\right)$ and Impedance $(\mathrm{M} \Omega)$ measured at the exterior insulation render layer are 
shown in Figure 6. After certain weathering cycles the plasters showed a moisture uptake in the impedance measurements. Such behaviour should be omitted in the final product development due to the risk of frost cracking.

Walls A-B
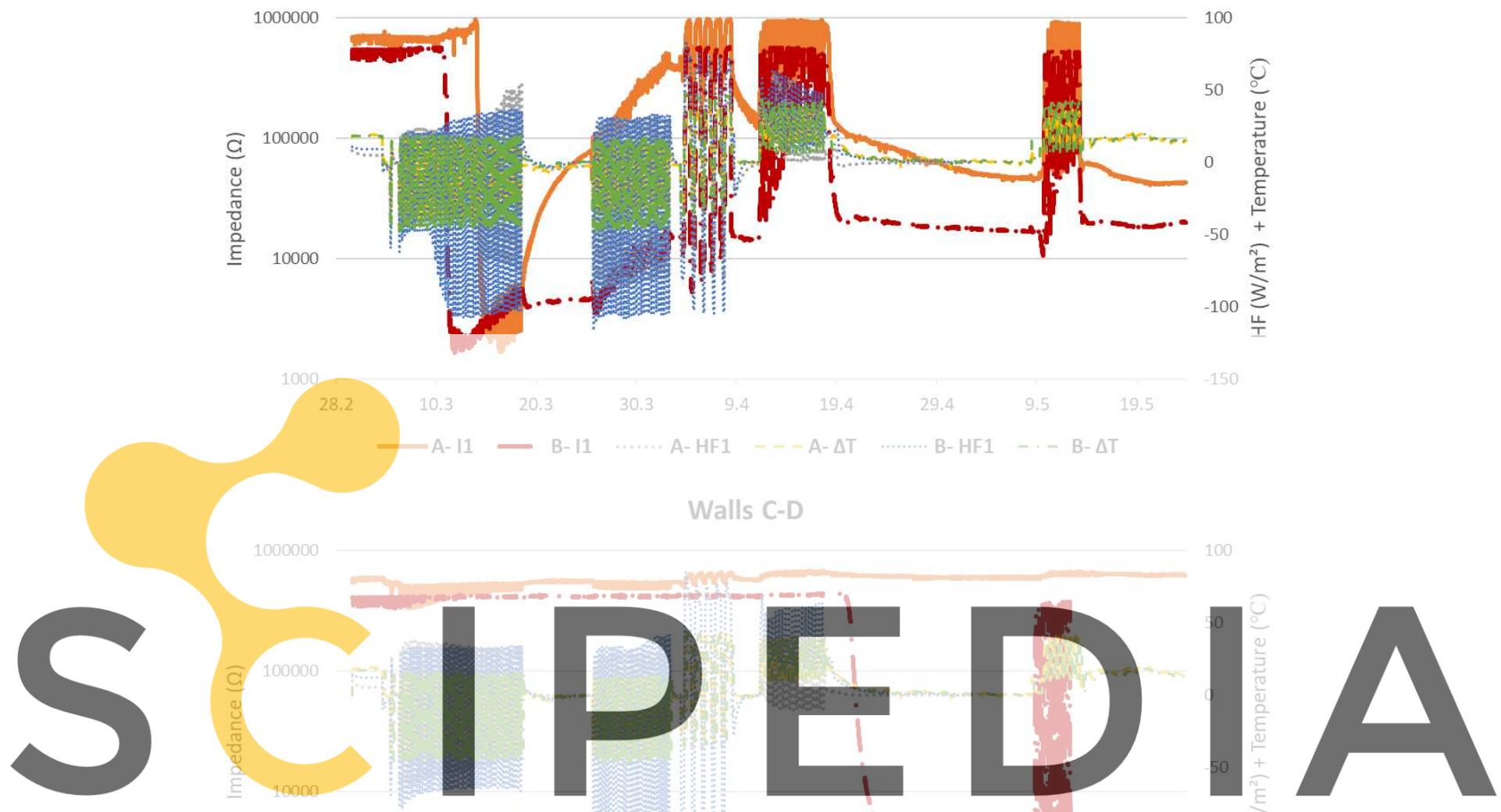

Register for free at https//www.scipedia.com to download the $\forall$ ersion without the watermark

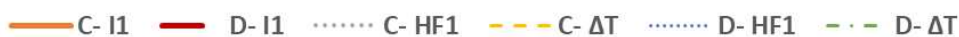

Figure 6. Temperature difference $\left({ }^{\circ} \mathrm{C}\right)$, heat flux $\left(\mathrm{W} / \mathrm{m}^{2}\right)$ and Impedance $(\mathrm{M} \Omega)$ measured during the EOTA test: (a) Wall A and B (Wall-ACE Quick-Mix Aerogel render); (b) Wall C and D (TRI-O-THERM render).

\subsubsection{Adhesive strength}

Results of adhesive strength (determined from the maximum load and the area of $2500 \mathrm{~mm}^{2}$ subjected to tensile stress) are given in Table 1. It can be seen that average adhesive tensile strength of aerogel-based exterior insulation render was 33-60\% lower after ageing compared to initial adhesive strength. These values (strength after ageing) are comparable with adhesive strength of TRI-O-THERM after ageing. The failure was $100 \%$ in the insulation render in all tests.

Before the start of the EOTA-Wall Test, the test wall was checked for its initial condition. No defects were found during the initial inspection. 
Table 1. Results of adhesive strength

\begin{tabular}{|c|c|c|c|c|}
\hline Substrate & $\begin{array}{l}\text { Render } \\
\text { type }\end{array}$ & Testing time & $\begin{array}{l}\text { Adhesive } \\
\text { strength } \\
{\left[\mathbf{N} / \mathbf{m m}^{2}\right]}\end{array}$ & Failure mode \\
\hline Hollow brick & \multirow{4}{*}{$\begin{array}{c}\text { QUICK- } \\
\text { MIX } \\
\text { WALL- } \\
\text { ACE }\end{array}$} & Before ageing & 0.009 & Specimen failure \\
\hline Light weight concrete & & Before ageing & 0.005 & Specimen failure \\
\hline Hollow brick & & After ageing & 0.003 & Specimen failure \\
\hline Light weight concrete & & After ageing & 0.003 & Specimen failure \\
\hline Hollow brick & \multirow{2}{*}{$\begin{array}{l}\text { TRI-O- } \\
\text { THERM }\end{array}$} & After ageing & 0.004 & Specimen failure \\
\hline Light weight concrete & & After ageing & 0.004 & Specimen failure \\
\hline
\end{tabular}

The test wall surface was observed during the EOTA test for changes such as cracks, chipping of surface, etc. Only minor chipping of surface was present after EOTA test. Furthermore, crack propagation (crack length/crack width) was observed for each window. Crack propagation is similar for both renders. Crack width is never bigger than $0.15 \mathrm{~mm}$ which is a sign for positive behaviour of tested systems.

\subsection{Test Field}

The weather data obtained from the experimental campaign (20/05/19 - 20/09/19) are shown in Figure 6. External conditions or outside environment measured by the sensors presented an average $26.5^{\circ} \mathrm{C}$ of air temperature, $52 \%$ of air relative humidity and $743 \mathrm{~W} / \mathrm{m}^{2}$ of global radiation since the analyse

The completion of th chart. Furthermore, in reading the humidity the material is still damp. A U-value estimation is foreseen fo

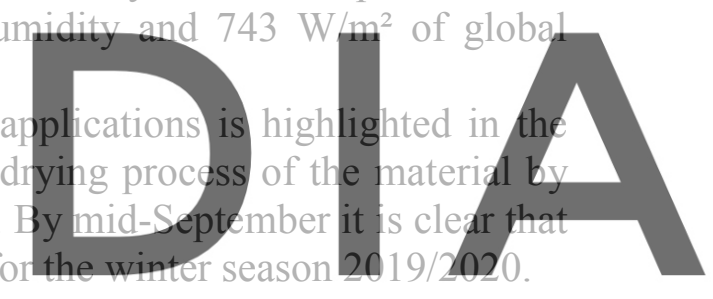

Register for free at https//www.scipedia.com to download the version without ${ }^{98}$ the watermark

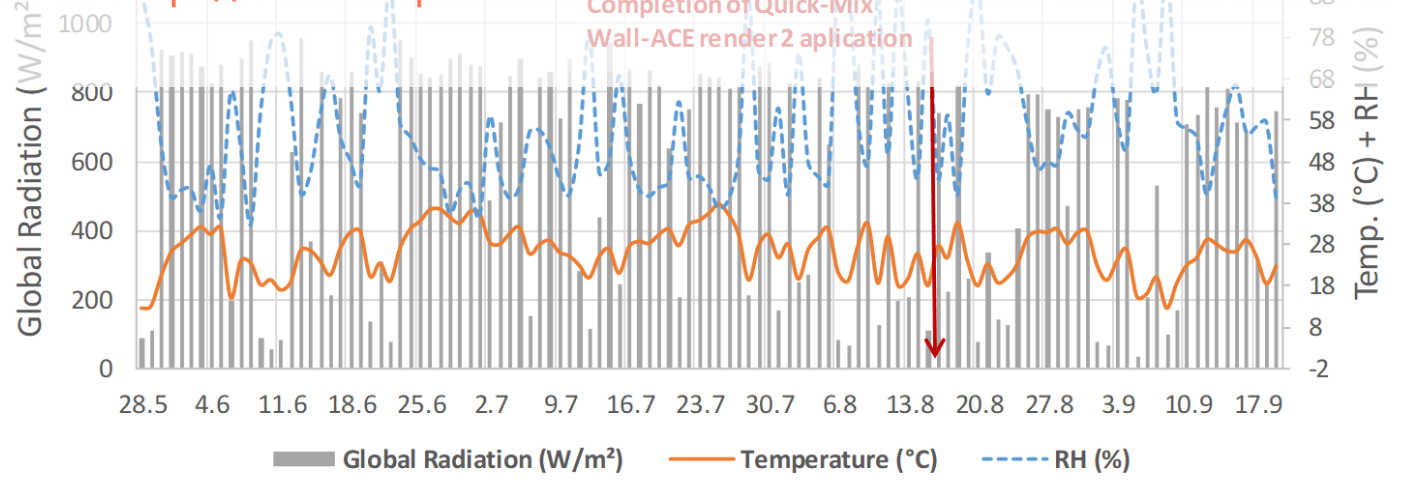

Figure 7. Environmental data at test side.

\section{Conclusions}

The large scale EOTA-Wall Test, originally developed for ETICS systems, is a valuable method to assess new developed insulation render systems. It provides a harsh environment and acts therefore as acceleration benchmark. Additional monitoring of certain parameters (moisture, 
climate, heat flux) within the material helps to assess energy performance under such conditions. First experiences (Frick et al., 2016) were further developed.

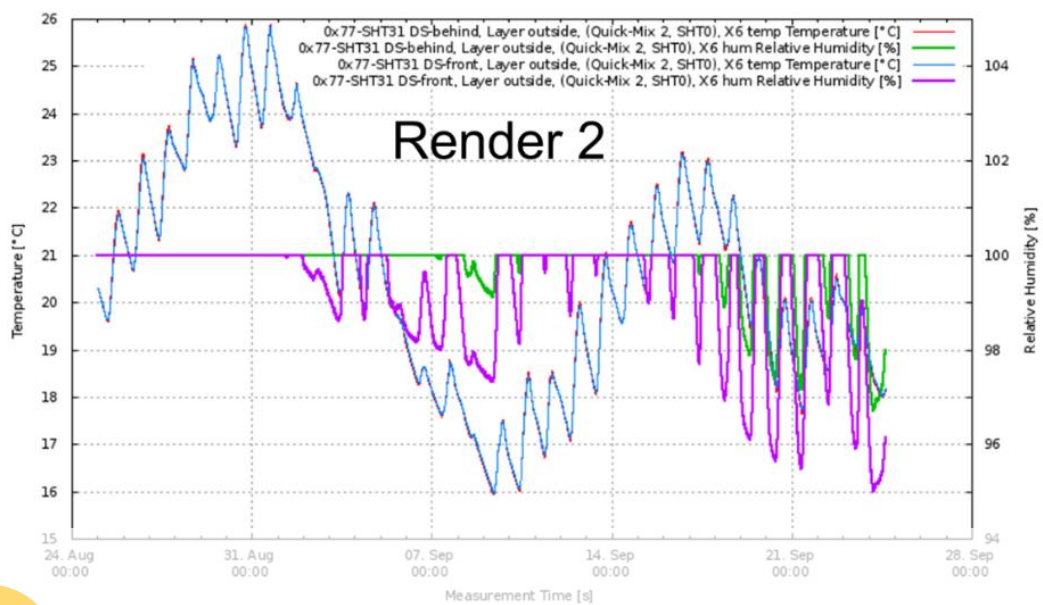

Figure 8. Temperature and relative humidity measured in the Quick-Mix render 2.

The field tests serve as benchmark in real conditions. The installation at the south side results in harsher conditions with higher temperature gradients. On the other side the estimation on energy performance parameters like U-values will be more difficult. Certain methodologies will be tested with the monitoring data from the upeoming winter season (Necentini Acknowledgements

The research project Wallprogramme under the Grant installed the different aerogel mater
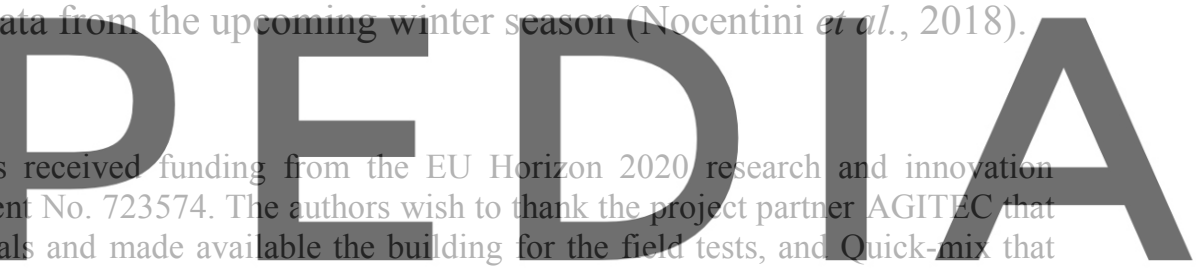

provided/installed the developed material in the experimental chamber.

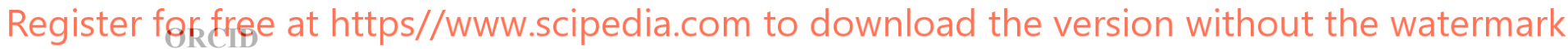

Jürgen Frick: https://orcid.org/0000-0002-2010-4830

Nayara R. M. Sakiyama: https://orcid.org/0000-0002-1928-4950

Harald Garrecht: https://orcid.org/0000-0002-7080-3197

\section{References}

CEN/TC 88 (2016). EN 16383: Thermal insulation products for building applications - Determination of the hygrothermal behaviour of external thermal insulation composite systems with renders (ETICS)

EOTA (2013). ETAG 004: Guidline for European Technical Approval of External Thermal Insulation Composite Systems (ETICS) with Rendering.

Frick, J., Reichert, M., Lehmann, F., Stegmaier, M. and Herter, K. (2016). Moisture Monitoring during an Artificial Weathering Test of a Cultural Heritage Compatible Insulation Plaster. In Proceedings of the $19^{\text {th }}$ World Conference on Non-Destructive Testing, Munich, Germany, paper Mo2C3, 1-7. https://www.wendt2016.com/portals/wendt/bb/Mo2C3.pdf [acc. 18-12-2019]

ISO/TC 163/SC 1 (2014). ISO 9869-1: Thermal insulation - Building elements - In-situ measurement of thermal resistance and thermal transmittance - Part 1: Heat flow meter method.

Nocentini, K., Achard, P. and Biwolé, P. (2018). Thermal performances of an innovative super-insulating material based on silica aerogel. In Proc. of $13^{\text {th }}$ Conference on Advanced Building Skins, Bern, Switzerland, 519-529.

Wall-ACE (2016). Wall-ACE - WALL Insulation NOvel Nanomaterials Efficient systems, EU Horizon 2020 project, Grant Agreement number: 723574, duration 2016-2019, https://www.wall-ace.eu/ [acc. 18-12-2109] 